\title{
Silage intake, rumination and pseudo-rumination activity in sheep studied by radiography and jaw movement recordings
}

\author{
BY A. G. DESWYSEN* AND H. J. EHRLEIN \\ Universität Hohenheim, Institut für Zoophysiologie, D-7000 Stuttgart 70, FRG
}

(Received 1 August 1980 - Accepted 22 April 1981)

1. The eating and ruminating activity of four rams given long-chopped silage ad lib. in two daily meals was studied by jaw movement recordings. The events of rumination and pseudo-rumination were observed by fluoroscopy and by cineradiog,raphy.

2. The rate of eating was highest at the beginning of the main meal and then declined gradually.

3. The silage intake level wis low.

4. The swallowed silage did not accumulate at the cardiac region but was forced into the dorsal sac of the rumen by the contractions of the reticulum and cranial sac of the rumen. For regurgitation the solid particles had to return via the ventral and cranial sac of the rumen into the reticulum.

5. Liquid reticular contents 'vith floating solid particles were aspirated into the oesophagus during the maximum of the regurgitation contraction of the reticulum.

6. The rumination activity during the day presented a high proportion of pseudo-rumination cycles whereas during the night the rumination became progressively normal.

7. Pseudo-rumination was caused by delayed return of the fibrous silage particles into the reticulum. Thus in pseudo-rumination the regurgitated material consisted predominantly of fluid containing only a small quantity of solid particles.

8. The results explain why long-chopped silage intake is associated with pseudo-rumination, a lower breakdown of particles and a waste of digestion time.

Generally it is found that the dry matter (DM) intake of silage is less than that from the original crop fed fresh or in a dried form, the difference being greater with sheep than with cattle (Campling, 1966; Demarquilly, 1973; Dulphy \& Michalet, 1975; Demarquilly \& Dulphy, 1977; Wilkins, 1978).

This lower level of intake could be related partially to the chemical composition of the silage and also to the physical structure of the ensiled forage. Finely chopping the grass before or after ensiling resulted in a significant increase of the DM intake (Dulphy \& Demarquilly, 1972, 1973; Dulphy et al. 1975; Deswysen et al. 1978).

With long- $v$. short-cropped silage, the total eating time was longer. However, the voluntary intake was lower, so that unitary eating time ( $\mathrm{min} / \mathrm{g} \mathrm{DM}$ per $\mathrm{kg}$ body-weight ${ }^{0.75}$ ) was significantly greater with long-chopped silage. The measured mean reticulo-rumen particle dimension after a meal of long-chopped silage was greater than with short-chopped silage, so it can be concluded that the chewing activity during intake must be insufficient to reduce the original longer silage particle dimension (Deswysen, 1980).

It would be expected that rumination stimuli would be increased by the presence of longer reticulo-rumen particles after feeding long-chopped silage. However, some incomprehensible results were found (Desiwysen, 1980): (1) latency time, i.e. period between the end of the main meal and the first rumination period, was increased; (2) the daily ruminating time was shorter, but the unitary ruminating time ( $\mathrm{min} / \mathrm{g}$ DM per $\mathrm{kg}$ body-weight ${ }^{0 \cdot 75}$ ) was slightly increased; (3) a great number of pseudo-rumination cycles occurred. Probably as a result of these events, the measured retention time of the indigestible fraction of long-chopped silage compared to short-shopped silage was significantly greater.

* Present address: Université Catholique de Louvain, Laboratorie de Biochimie de la Nutrition, Place Croix de Sud, 3, Sc. 15 D 2, B-1348 Luuvain-la-Neuve, Belgium. 
Table 1. The chemical composition of the silage ( $\mathrm{g} / \mathrm{kg}$ dry matter (DM))

\begin{tabular}{lcc}
\hline \hline & 268 \\
Mean particle length $(\mathrm{mm})$ & 408 \\
DM $(\mathrm{g} / \mathrm{kg})$ & $4 \cdot 62$ \\
$\mathrm{pH}$ & $44 \cdot 1$ \\
Ammonia-nitrogen $(\mathrm{g} / \mathrm{kg}$ total $\mathrm{N})$ & 115 \\
Crude protein $(\mathrm{N} \times 6 \cdot 25)$ & 353 \\
Crude fibre & 909 \\
Organic matter & $26 \cdot 0$ \\
Acetic acid & $14 \cdot 0$ \\
Butyric acid & $57 \cdot 4$ \\
\hline
\end{tabular}

The aim of this paper was to clarify the reason for this delayed and abnormal rumination activity by the sheep fed on long-chopped silage, as well as to examine if the lower voluntary intake level of silage compared to grass or hay could be due to an accumulation of ingesta in the cardiac area as suggested by Dulphy \& Demarquilly (1973).

\section{EXPERIMENT A L}

Materials and methods

Silage. The first cut of mixed herbage grass was ensiled as long pre-wilted grass in plastic sacks $(10-15 \mathrm{~kg})$. which were sealed and stored for 2 months at room temperature.

Physical measurements and chemical analysis. The mean size of particles in the silage was determined on dried silage by a sieving method using a mechanical shaker followed by hand-picking on paper marked in $\mathrm{mm}$ and the mean particle dimension was calculated.

DM concentration of the silage was determined by drying at $105^{\circ}$ in a forced-draught oven to a constant weight and corrected for the volatile losses by the method proposed by Schoch (1949).

Samples of silage were analysed, where appropriate, for $\mathrm{pH}$, organic acids, ammonia, crude protein (nitrogen $\times 6.25 ; \mathrm{CP}$ ), crude fibre (CF) and organic matter (OM).

The chemical composition of silage is shown in Table 1.

Animals and management. Four 5-month-old healthy German Merino rams $(27 \cdot 2 \pm 3.9 \mathrm{~kg}$ average weight) were used in these experiments.

They were trained to be tractable and to eat and ruminate freely during the course of the cinefluoroscopic observations. The sheep were normally housed in groups of two in straw-bedded floor pens. The two animals of each group were trained together to be restrained in individual solid-floor pens. For fluoroscopy they stood on a special rack and were positioned in a hammock. In order to accustom the animals to the experimental surroundings, they were placed daily on the rack for more than $2 \mathrm{~h}$ before the actual observations were made. They were allowed free access to silage throughout the periods of familiarization with the experimental surroundings and during the actual observation of the intake activity, but not during the rumination activity.

The sheep were fed silage ad lib. in two daily meals at 09.00 and 16.00 hours. They received also $100 \mathrm{~g}$ concentrates each morning. Silage refusals were removed at 08.45 hours each day. The animals had ad lib. access to drinking water.

The experiment lasted $31 \mathrm{~d} ; 10 \mathrm{~d}$ adaptation to the silage ration, $16 \mathrm{~d}$ adaptation to being tied and placed in a frame in the room with the radiographic equipment and during radiographic observation trials, $5 \mathrm{~d}$ of actual fluoroscopic records.

Jaw movement recordings. The voluntary silage intake and the eating and ruminating behaviour were recorded during the 24 and 25 th days of the experiment. The sheep were 
Table 2. The voluntary try matter (DM) intake and the eating and ruminating activity of the four sheep fed on long-chopped grass silage

\begin{tabular}{|c|c|c|c|c|c|c|}
\hline Sheep & $\mathbf{M}$ & $\mathbf{G}$ & $\mathbf{K}$ & $\mathbf{S}$ & Mean & $\mathbf{S E}$ \\
\hline Daily DM intake (g/kg W0.75) & $47 \cdot 0$ & $38 \cdot 8$ & $51 \cdot 5$ & $44 \cdot 6$ & $45 \cdot 5$ & $2 \cdot 7$ \\
\hline Eating time $(\min / \mathrm{d})$ & 351 & 353 & 306 & 337 & 337 & 10.9 \\
\hline $\begin{array}{l}\text { Unitary eating time } \\
(\mathrm{min} / \mathrm{g} \text { DM per kg W0.75) }\end{array}$ & 7.5 & $9 \cdot 1$ & 5.9 & 7.6 & $7 \cdot 5$ & 0.7 \\
\hline No. of meals $(/ \mathrm{d})$ & 8.5 & 6.5 & 6.0 & $10 \cdot 5$ & 7.9 & 1.0 \\
\hline Mean latency time (min) & 1.0 & 3.6 & 32.5 & 4.8 & $10 \cdot 5$ & 14.8 \\
\hline Ruminating time ( $\min / \mathrm{d})$ & 488 & 467 & 653 & 607 & 554 & $45 \cdot 2$ \\
\hline $\begin{array}{l}\text { Unitary ruminating time } \\
\text { (min/g DM per } \mathrm{kg} \mathrm{W}^{0 \cdot 75} \text { ) }\end{array}$ & 10.4 & 12.0 & $12 \cdot 7$ & 13.6 & $12 \cdot 2$ & 0.7 \\
\hline $\begin{array}{l}\text { No. of ruminating } \\
\text { periods }(/ d)\end{array}$ & 16.5 & 15.5 & 12.5 & 13.5 & 14.5 & 0.9 \\
\hline $\begin{array}{l}\text { No. of ruminating } \\
\text { cycles }(/ d)\end{array}$ & 633 & 777 & 798 & 924 & 783 & $59 \cdot 6$ \\
\hline $\begin{array}{l}\text { Pseudo-rumination } \\
\text { ( } \% \text { cycles } / \mathrm{d})\end{array}$ & $6 \cdot 3$ & 38.0 & 16.4 & 8.9 & 17.4 & $7 \cdot 2$ \\
\hline $\begin{array}{l}\text { Mean duration of one } \\
\text { rumination cycle (min) }\end{array}$ & 0.8 & 0.6 & 0.8 & 0.7 & 0.7 & 0.05 \\
\hline
\end{tabular}

W, body-weight.

harnessed for a minimum of $5 \mathrm{~d}$ before the beginning of the jaw movement recordings which were continuously recorded by the method of Ruckebusch (1963). The pressure changes resulting from the jaw rnovements, were also recorded through an electronic pressure transducer (Statham) and a multichannel recorder (Hellige, Freiburg, FRG).

Radiography. For cineradiographic and fluorographic studies an X-ray image intensifier (Siemens, Erlangen, FRC) with a TV-camera, videotape recorder and $35 \mathrm{~mm}$ cine-camera (Arnold \& Richter, Muerchen, FRG) were used. Radiographs $(100 \times 100 \mathrm{~mm})$ were taken during fluoroscopy by a Sircam-camera.

In order to follow simultaneously jaw movement records and fluoroscopic events of rumination, the jaw movement tracings were picked up with a second TV-camera, displayed together with the fluoroscopic picture on a TV-screen and recorded at the same time on the videotape.

Cineradiographic films $(35 \mathrm{~mm})$ were produced with a speed of 25 frames/s. Each X-ray sequence could last up to $1 \mathrm{~min}$ by automatic control of the temperature of the X-ray tube.

Because fluoroscopic observation and recording on videotape were not limited by radiation dosage, food intaice, rumination, pseudo-rumination and movement of food within the forestomachs were followed for several hours.

Barium sulphate suspension or Micropaque was administered orally or with the silage. Coating of silage with Micropaque was done a few hours before feeding in order to increase palatibility.

\section{RESULTS}

Volur!tary intake, eating and ruminating activity

The results of the voluntary silage intake and of the eating and ruminating activity are given in Table 2. The pattern of eating and ruminating during $24 \mathrm{~h}$ are shown in Fig. 1 . It presents a typical nyctohemeral variation of the jaw movement activity.

The voluntary DM intake was rather low, but normal for this kind of silage. 


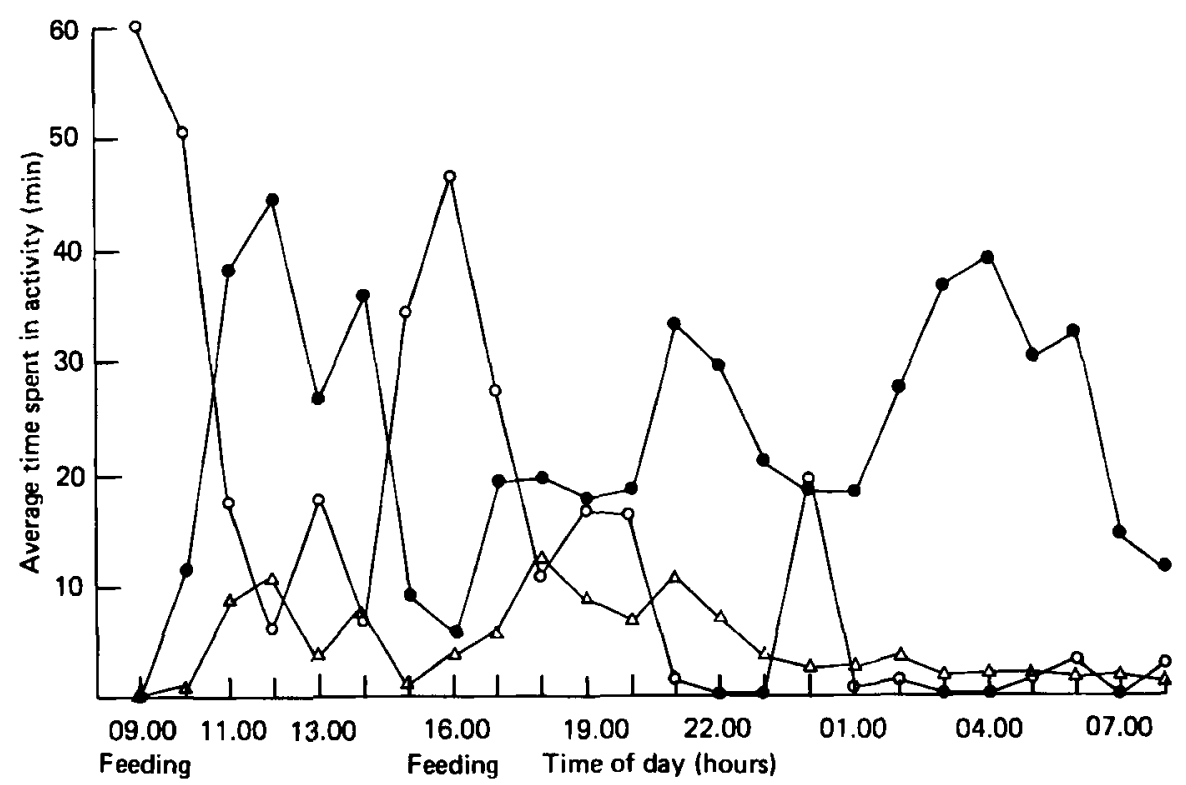

Fig. 1. Average times spent in: intake $(O)$; rumination $(O)$; pseudo-rumination $(\triangle)$ by sheep receiving long-chopped grass silage ad lib.

The eating and ruminating behaviour varied greatly between animals, especially for the rumination activity (total ruminating time, number of cycles, percentage pseudo-. rumination).

The period between the end of the main meal and the first rumination activity, denoted as latency time, was very short (mean $10.5 \pm 14.8 \mathrm{~min}$ ).

\section{Eating behaviour}

The characteristic recordings of jaw movements during a main meal of silage are presented in Plate 1. Food intake was interrupted by selecting and prehension intervals which were longest at the end of the meal. The chewing rate and the number of swallows per unit time were thus highest at the beginning of the meal and lowest at the end.

\section{Movement of food boli through the reticulo-rumen}

Radiographic studies during eating have shown that each swallowed bolus was projected into the reticulo-rumen with considerable force and deposited in the upper part of the reticulum near the reticulo-ruminal fold. Two or three swallowed boli accumulated there before the reticulum contracted and moved them rapidly aborally into the cranial sac of the rumen. The succeeding contraction of the cranial sac forced the coarse material over the contracting cranial pillar into the dorsal sac of the rumen, while the fluid contents of the cranial sac returned into the relaxing reticulum. These aboral movements of swallowed boli were observed throughout the meal. Some food particles returned directly from the dorsal sac of the rumen into the upper part of the reticulum during the primary contraction of the dorsal sac of the rumen and relaxation of the reticulum. These particles, however, were forced back again into the dorsal sac by the following contractions of the reticulum and of the cranial sac.

When the dorsal sac of the rumen was filled with $\mathrm{BaSO}_{4}$-coated swallowed material, it was forced downwards into the caudo-ventral blind sac of the rumen (Fig. 2). 
(A)

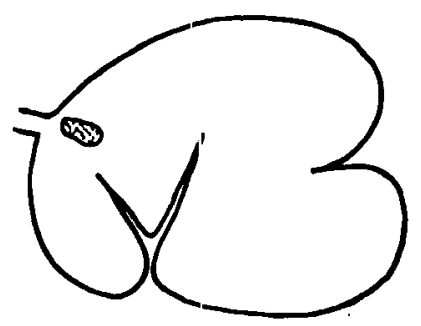

(C)

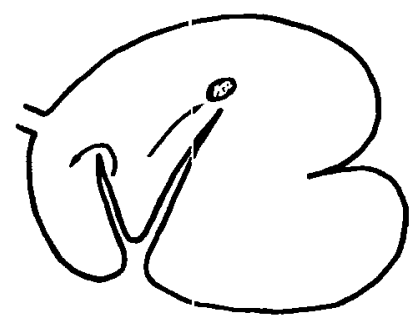

(B)

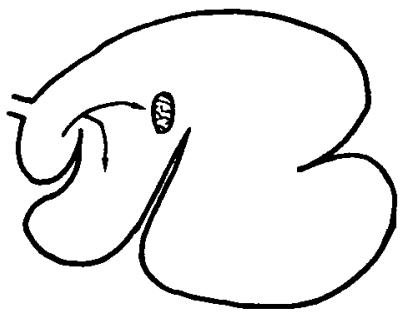

(D)

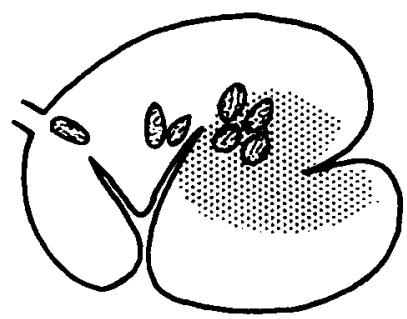

Fig. 2. Movement of food boli from the reticulum into the rumen. (A) Food bolus in the reticulum immediately after swallowing; (B) displacement of the bolus from the reticulum into the cranial sac of the rumen by the diphasic reticular contractions; (C) upwards movement of the bolus over the cranial pillar and backflow of fluid contents into the relaxing reticulum by the contraction of the cranial sac of the rumen; (D) accumulation of coarse food particles in the dorsal rumen, in the middle of the rumen and in the caudoventral blindsac of the rumen.

\section{Rurnination and pseudo-rumination behaviour}

The rumination activity started at a mean interval of $10.5+14 \cdot 8 \mathrm{~min}$ after the end of the two daily main meals (morning and evening). During the day when the sheep ate several times a high proportion of pseudo-rumination occurred whilst in the first part of the night the rumination became prc gressively more normal. In the early morning pseudo-rumination disappeared completely, because there was no more silage intake during the night (Plate 2).

\section{Normal rumination}

Jaw movement recordings. As shown in Plate 3, the normal rumination activity was characterized by successive cycles with approximately the same number (67-84) and strength of chews. Some shorter rumination cycles (31-54 chews) occurred also. The duration of the interval tetween cycles, denoted as intercycle, was very regular (5-6s). Within each normal rumination cycle, the chews were very regular and at the end of each cycle the rate of chewing v/as often a little higher and the strength lower, probably to make up the structure of the rumination bolus (solids and liquids) to be reswallowed (Plate 3).

Radiographic observations. The events of regurgitation, remastication and redeglutition during rumination and pseudo-rumination were observed fluoroscopically and cinefluoroscopically in four sheep over periods of some hours. Regurgitation occurred just before the beginning of the normal reticulo-ruminal motility cycle. It was associated with the separate 'regurgitation' contraction of the reticulum and followed by the normal diphasic reticular contraction. By the regurgitation contraction, coarse material was forced from the upper part of the reticulum into the cranial sac of the rumen and the contents of the lower part of the reticulum were car ried to the cardia. Aspiration of ingesta (fluid containing small particles) into the thoracic oesophagus occurred at the maximum of the regurgitation contraction. 
Facing the thoracic oesophagus it was seen at each regurgitation that all the aspirated material was carried orally extremely quickly by an antiperistaltic contraction and that, after a short break, two swallowed boli of contrast medium returned towards the reticulum.

Facing the neck and head it could be observed that all the regurgitated material returned to the mouth. During the first jaw movement for each rumination-bolus the fluid contents of the regurgitated material were squeezed and immediately swallowed, so that the time difference between arrival of the material in the mouth and redeglutition was approximately $0.25 \mathrm{~s}$. About two seconds later, at the 4-5th chew of the rumination cycle, the regurgitated contents were again squeezed and the fluid swallowed.

The solid contents of the regurgitated material were remasticated and reswallowed in two to four swallowed boli: deglutition of the last bolus occurred before the reticulo-rumen cycle was finished. The jaw movements ceased for 5-6 s and the next regurgitation started with a regurgitation contraction of the reticulum just before the beginning of the next reticulo-rumen cycle. It was often seen that gas from the reticulo-rumen entered the oesophagus. This ocurred most often during the second deglutition of the squeezed fluid at the 4-5th chew. Sometimes the gas was aspirated to the trachea, sometimes it was retained in the oesophagus and was forced back into the reticulum together with the remasticated material.

\section{Pseudo-rumination}

Jaw movement recordings. The pseudo-rumination activity shown in Plate 3, presents very irregular rumination-cycles with a lower number of chews per cycle (3-20 chews); each chew except the first was of lower strength than in normal rumination. The interval between cycles was very irregular and notably longer (4-48 s).

Radiographic abservations. The events of pseudo-rumination were similar to the normal rumination except that a very large part, or sometimes all, of the regurgitated contents which arrived in the mouth, flowed back rapidly into the reticulo-rumen. When the quantities regurgitated were very small, the second squeezing at the 4-5th chew did not occur. After a few chews the small amount of solid material was reswallowed before the end of the reticulo-rumen cycle.

\section{DISCUSSION \\ Eating behaviour}

As shown by the jaw movement recordings the eating activity varied considerably during a meal. Schalk \& Amadon (1928) demonstrated on mature cows that the eating rate was much higher at the beginning of the meal especially after a $24 \mathrm{~h}$ fasting period. In the present experiments with sheep fed silage ad lib. a much higher number of swallows per unit time was found at the beginning of a main meal (Plate 1). Similar results were found by Suzuki et al. (1969) and Owen et al. (1976).

Dulphy \& Demarquilly $(1972,1973)$ found on sheep that the DM intake of silages with different qualities and different chop length was much lower during the two daily main meals than that of corresponding hay or fresh grass. They suggested that this rapid satiety specific to silage rations could be due to an obstruction of the cardiac region by the swallowed silage. The present radiographic studies revealed no accumulation of swallowed material in the cardiac area. All the swallowed silage was forced rapidly backwards into the dorsal sac of the rumen by contractions of the reticulum and the cranial sac of the rumen. Akester \& Titchen (1969) also observed in sheep that light particles (coated dog biscuit) were displaced from the reticulum into the dorsal sac of the rumen. Therefore it seems doubtful that the lower voluntary intake level of silage compared to grass or hay is caused by an obstruction of the cardiac area. 


\section{Normal rumination}

The mechanism of rumination has been intensively studied in sheep by Bell (1958) and in cattle by Stevens \& Selle:s (1960). However, fluoroscopic studies to visualize the mechanical events of rumination have been used only by Czepa \& Stigler (1929). Probably the reason for this may be that rumination only occurs when the animals are accustomed to the experimental conditions. Therefore, rumination studies by radiograpy require much time and patience. The separate 'regurgitation' contraction of the reticulum as could be seen by radiography had already been found in cattle from palpation by Wester (1926), Bergmann \& Dukes (1926), Schalk \& Amadon (1928). However, the significance of the contraction of the reticulum is not completely clear. Bell (1958) suggested that in sheep the reticular contraction increases pressure in the forestomachs and supports the entrance of the regurgitated material in the thoracic oesophagus, whilst in cattle no significant increase in pressure near the cardia by the reticular contraction was found (Stevens \& Sellers, 1960). In fluoroscopy the passige of a bolus from the reticulum into the oesophagus cannot be observed because the difference of contrast between the thorax and the fluid-filled reticulum is too large. It can be seen, however, that coarse material in the upper part of the reticulum is forced into the cranial sac of the rumen by the reticular contractions and that aspiration of the bolus occurs at the maximum of the 'regurgitation' contraction. From this observation it can be concluded that the regurgitated digesta are coming from the lower part of the reticulum and consist predominantly of fluid with floating food particles. The function of the reticular contraction, therefore, will be primarily to clear the cardia of rough material and to flood it with fluid digesta containing food particles.

Little attention has been given to explain in which way the swallowed coarse material may return from the dorsal sac of the rumen back into the reticulum in order to be ruminated. Studies on reticulo-rumen motility and movement of digesta have shown (Ehrlein, 1979) that the coarse material of the dorsal sac is slowly rotated, squeezed and again mixed with fluid by the contractions of the wall and of the pillars of the rumen. Thereby food particles are flushed into the ventral sac of the rumen. From the ventral sac they return into the cranial sac because the cranial pillar moves ventrally during the contraction of the ventral sac of the rumen. During the contraction of the cranial sac they return into the reticulum. From the reticulum, particles sufficiently ground pass into the omasum whilst larger particles are ruminated.

The material aspirated into the oesophagus was forced into the mouth extremely rapidly. This is in agreement with: results of Stevens \& Sellers (1960) in cattle; they have found that the antiperistaltic wave of the oesophagus during regurgitation travelled much more quickly than the peristaltic wave during swallowing of saliva. When the regurgitated material arrived in the mouth small amounts were immediately reswallowed in separate deglutitions. These events have already been observed by Magee (1932) and were suggested by Downie (1954) from recording of jugular pulse.

\section{Pseudo-rumination}

Irregular jaw movement 1racings similar to our pseudo-rumination recordings were reported from cows fed on ground hay (Balch, 1952, 1971; Freer \& Campling, 1965), from sheep fed on a concentrate meal diet (Gordon, 1958), on sheep during fasting (Welch \& Smith, 1968), and after intraraminal administration of single doses of $150 \mathrm{~g}(300 \times 2 \mathrm{~mm})$ polypropylene ribbon (Welch \& Smith, 1971). The recorded disturbance of rumination in a goat after ablation of the orbito-frontal lobes of the cerebral cortex gave similar jaw movement tracings (Bell \& Lawn, 1957).

The reason and the events of the pseudo-rumination were not exactly known. The present 
radiographic studies have shown that in pseudo-rumination the aspirated material is made up of mainly liquids and a small quantity of fibrous particles. This is in agreement with the assumption of other authors (Bell \& Lawn, 1957; Pearce \& Moir, 1964; Welch \& Smith, 1968; Ruckebusch et al. 1970), but had not been proven.

It is surprising that by feeding long-chopped silage the period of rumination decreases with an increase in proportion of pseudo-rumination. It would be expected that the coarse material of long-chopped silage present in the reticulo-rumen would stimulate the rumination.

As the radiographic studies have shown the swallowed fibrous material is not directly aspirated from the cranial sac of the rumen after deglutition but is forced backwards into the dorsal and ventral sacs of the rumen. From the ventral sac smaller fibrous particles can flow back over the cranial pillar into the cranial sac and reticulum in order to be aspirated into the oesophagus for rumination. By feeding long- $v$. short-chopped silage, it has been found (Campling, 1966; Dulphy et al. 1975; Deswysen, 1980) that the particles in the rumen were longer and more interwoven. Probably as a result of this, the separation and mechanical breakdown of the particles is made difficult, so that the transfer of small particles from the dorsal sac into the ventral sac of the rumen and the backflow into the cranial sac and reticulum is delayed. Therefore, during the period after food intake, not enough solid food particles are present in the reticulum, where the most potent reflexogenic zones for rumination are localized (Iggo \& Leek, 1970; Leek \& Harding, 1974). Thus with long-chopped silage usually pseudo-rumination occurs in the first period after silage intake during the day, and the beginning of rumination activity is delayed. In the present experiments, however, the rumination activity occurred very early after the end of the main meals $(10.5 \mathrm{~min} v .132$ and $141 \mathrm{~min}$ in previous studies) probably due to an abnormal stimulation during the silage intake.

In the light of the present results a partial explanation of the underlying physiological basis for the lower voluntary intake of long-chopped silage compared to short-chopped silage, is the delayed and less efficient mechanical breakdown of the particles by the pseudo-rumination activity, so that the reticulo-rumen retention time of the indigestible fraction of long-chopped silage is increased, which negatively influences the voluntary intake.

The authors are grateful to Dr H. Birnkammer, Betriebsleiter der Versuchsstation für landwirtschaftliche Betriebswirtschaft und Agrartechnik der Universität Hohenheim, for lending the animals.

A.G.D. acknowledges the financial support of the Institute pour la Recherche Scientifique en Industrie et en Agriculture and thanks Professor M. Vanbelle, Head of the Department in Louvain-la-Neuve, for providing the opportunity to perform this work in Hohenheim.

\section{REFERENCES}

Akester, A. R. \& Titchen, D. A. (1969). J. Anat. 104, 137.

Balch, C. C. (1952). Br. J. Nutr. 6, 366.

Balch, C. C. (1971). Br. J. Nutr. 26, 383.

Bell, F. R. (1958). J. Physiol., Lond. 142, 503.

Bell, F. R. \& Lawn, A. M. (1957). Br. J. Anim. Behav. 4, 125.

Bergmann, H. D. \& Dukes, H. H. (1926). J. Am. vet. Med. Ass. 69, 600.

Campling, R. C. (1966). J. Br. Grassld Soc. 21, 41.

Czepa, A. \& Stigler, R. (1929). Fortschr. Naturw. Forsch. 6, 1.

Demarquilly, C. (1973). Annls Zootech. 22, 1.

Demarquilly, C. \& Dulphy, J. P. (1977). Proc. Ist Mtg, Anim. Prod. Temperat. Grassld, Dublin, p. 53.

Deswysen, A. G. (1980). Studies on the effect of fineness and organic acids on the feeding value of grass silage. PhD Thesis, Université Catholique de Louvain, Belgium.

Deswysen. A. G., Vanbelle, M. \& Focant, M. (1978). J. Br. Grassld Soc. 33, 107.

Downie, H. G. (1954). Am. J. vet. Res. 15, 217. 
British Journal of Nutrition, Vol. 46, No. 2

Plate 1

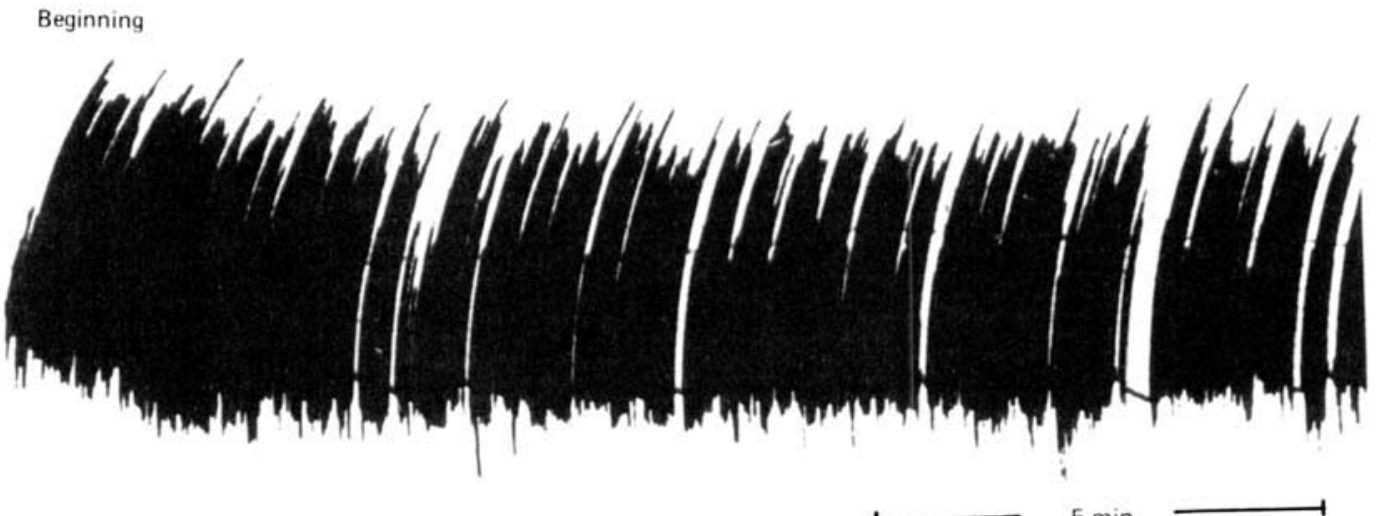

Middle

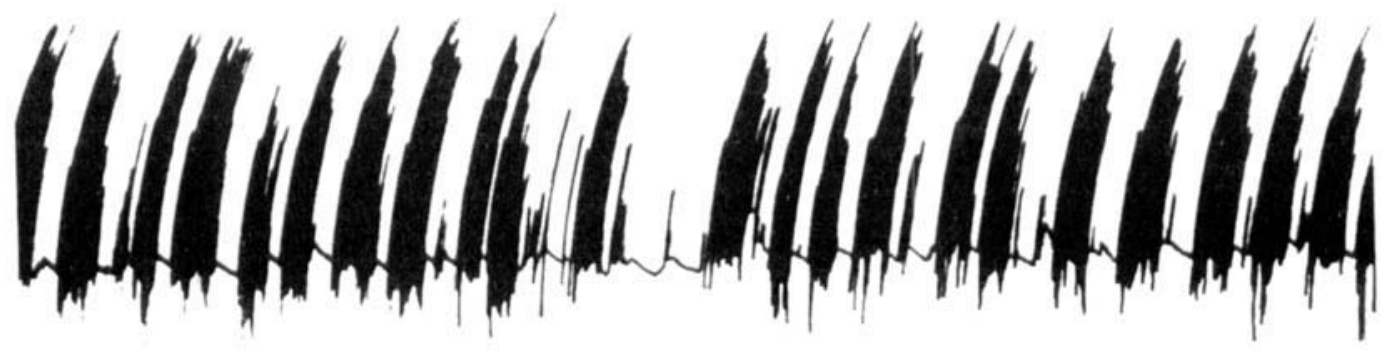

End

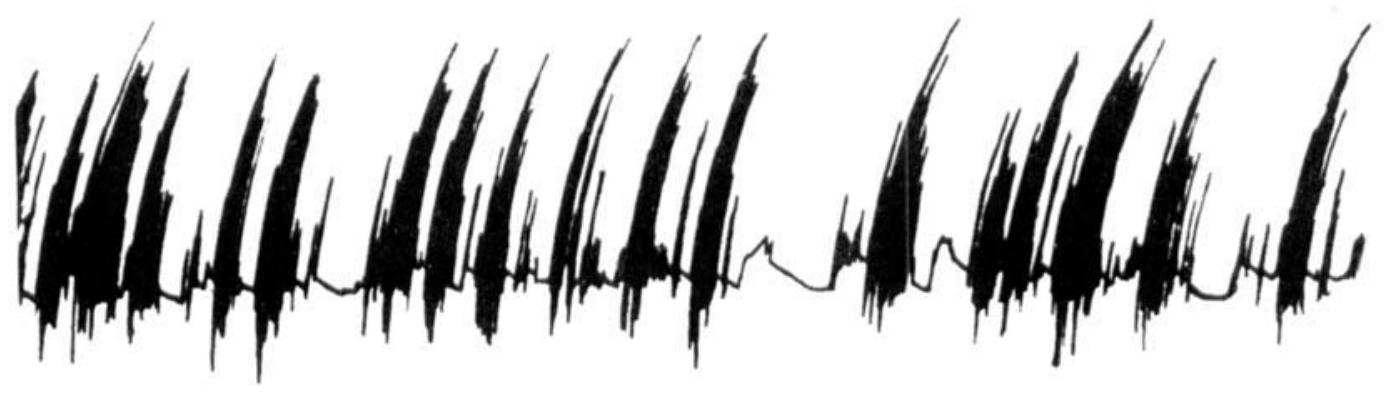




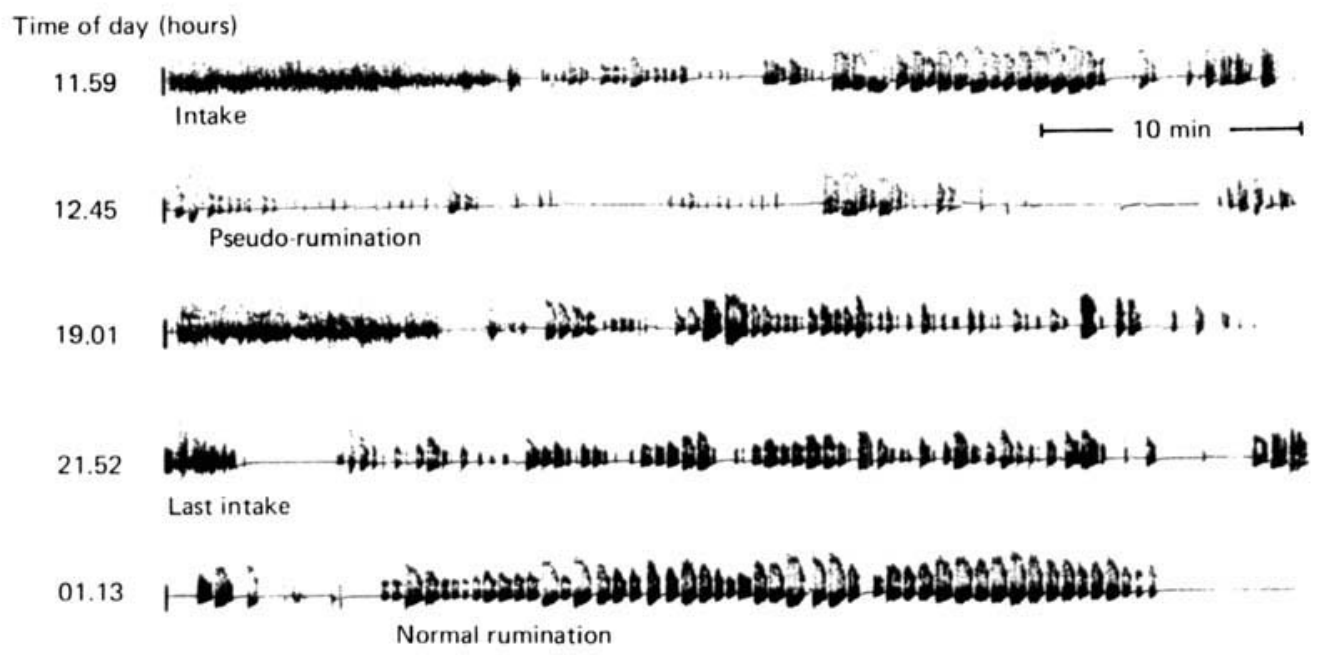

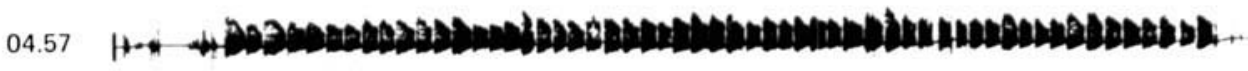

07.25

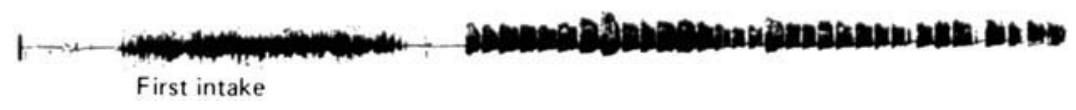



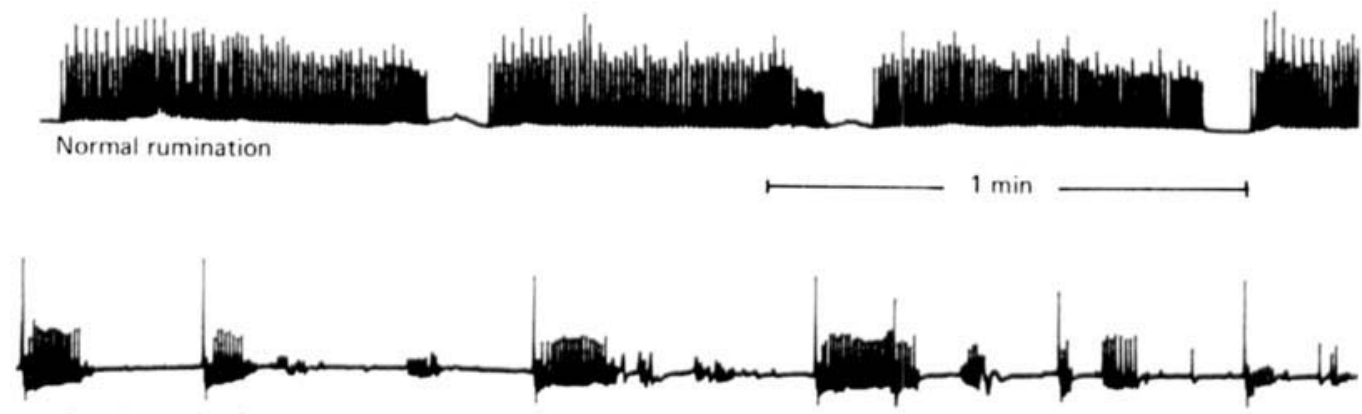

Pseudo-rumination 
Dulphy, J. P., Bechet, G. \& Thomson, E. (1975). Annls Zootech. 24, 81.

Dulphy, J. P. \& Demarquilly, C. (1972). Annls Zootech. 21, 443.

Dulphy, J. P. \& Demarquilly, C. (1973). Annls Zootech. 22, 199.

Dulphy, J. P. \& Michalet, B. (1975). Annls Zootech. 24, 757.

Ehrlein, H. J. (1979). Motility of the Forestomachs in Ruminants. Göttingen, Germany: Institut Wiss. Film.

Freer, M. \& Campling, R. C. 1965). Br. J. Nutr. 19, 195.

Gordon, J. G. (1958). J. agric. Sci., Camb. 50, 34.

Iggo, A. \& Leek, B. F. (1970). Physiology of Digestion and Metabolism in the Ruminant. Newcastle-upon-Tyne: Oriel Press.

Leek, B. F. \& Harding, R. H. (1974). Proc. 4th int. Symp. Anim. Physiol., Sydney, p. 18.

Magee, H. E. (1932). J. exp. Biol. 9, 409.

Owen, G. L., Martz, F. A., Canpbell, J. R., Matches, A. G. \& Hilderbrand, E. S. (1976). J. Anim. Sci. $42,1534$.

Pearce, G. R. \& Moir, R. J. (1964). Aust. J. agric. Res. 15, 635.

Ruckebusch, Y. (1963). Research on the central regulation of feeding behaviour in ruminants. PhD Thesis, Université de Lyon.

Ruckebusch, Y., Fargeas, J. \& Dumas, J. P. (1970). Rev. Méd. Vét. 121, 345.

Schalk, A. F. \& Amadon, R. S. (1928). Bull. North Dakota agric. Exptl. Stat., Fargo, no. 216, p. 3.

Schoch, W. (1949). Mitteil. Gebiet Lebensmittelunters. Hyg. 40, 170.

Stevens, C. E. \& Sellers, A. F. (1960). Am. J. Physiol. 199, 598.

Suzuki, S., Fujita, H. \& Shinds, Y. (1969). Anim. Prod. 11, 29.

Welch, J. G. \& Smith, A. M. (.968). J. Anim. Sci. 27, 1734.

Welch, J. G. \& Smith, A. M. (.971). J. Anim. Sci. 33, 1118.

Wester, J. (1926). Die Physiolo zie und Pathologie der Vormägen beim Rinde. Berlin: Richard Schoetz.

Wilkins, R. J. (1978). Proc. 3ra' Wld. Congr. Anim. Fedn., Madrid, p. 402.

\section{EXPLANATION OF PLATES}

Plate 1. Typical jaw movement jatterns of sheep during silage intake indicating eating behaviour at the beginning, middle and end of the main morning meal.

Plate 2. Typical intake activity and pseudo-rumination during the day (upper four tracings) and normal rumination activity during the night. (lower three tracings) for sheep $G$.

Plate 3. Detailed patterns of rumination and pseudo-rumination activity, showing rhythmic long-lasting chewing periods and short breaks during normal rumination. During pseudo-rumination there were few chews which occurred less regularly with lorig breaks. $\uparrow$, Swallowing of saliva. 